\title{
La cartografía de las ciudades históricas: entre la realidad y el proyecto
}

Eduardo Mosquera Adell, Escuela Técnica Superior de Arquitectura, Universidad de Sevilla

Desde el reconocimiento de que las ciudades son un cualificado escenario de la vida, y que constituyen realidades patrimoniales de especial trascendencia, se ha efectuado una aproximación a sus cartografías. Unos instrumentos gráficos que, por un lado, forman parte del propio patrimonio de las ciudades, pero que constituyen una herramienta indispensable para el conocimiento y para cualquier actividad de investigación, de protección y, en general, de gestión patrimonial sobre nuestras ciudades históricas.

Recorriendo básicamente los últimos cinco siglos de forma diacrónica, se considera la temática tanto dentro de una perspectiva internacional, como en el seno de la propia evolución de la cartografía urbana en la cultura hispánica, poniendo énfasis en el ámbito andaluz. Se hace asimismo particular hincapié en el progreso de las técnicas gráficas, hacia visiones cada vez más precisas y racionalizadas, basadas en proyecciones ortogonales.

\section{La aproximación a la cartografía funcional para el control} y gobierno de la ciudad heredada y para la definición de la ciudad proyectada, en la perspectiva de su crecimiento y desarrollo, recorre un ciclo cultural que tiene en la Ilustración unos logros especialmente relevantes. Se suman también los factores, aun más contemporáneos, derivados de la aparición de las modernas disciplinas urbanísticas y el empleo de la cartografía con nuevos matices e intencionalidades, también patrimoniales. La cartografia termina entonces por reflejar con mayor intensidad el cambio social, considerando cuestiones como el interés empresarial, el desarrollo del turismo y otras dinámicas que inciden en el tratamiento de las ciudades históricas.

\section{Palabras clave}

Arquitectura / Cartografías / Ciudades históricas / Investigación / Paisaje / Patrimonio cultural / Planos / Urbanismo / Vistas de ciudades
El trabajo patrimonial requiere del beneficio de un conocimiento riguroso. La actividad investigadora vinculada a su sustancia histórica o cultural se nutre de múltiples recursos, muchos de los cuales también constituyen, por si mismos, patrimonio. Nuestras ciudades históricas no sólo son realidades basadas en complejos artificios identificados por la agrupación y convivencia de inmuebles, en forma de edificaciones y espacios libres, o de bienes muebles asociados o contenidos, todos ellos testimonio de los tiempos, de los episodios físicos que las han modelado diacrónicamente. También esas ciudades incluyen en su condición y en sus valores patrimoniales múltiples asociaciones y manifestaciones inmateriales. La suma de todo ello las reivindica como cualificados escenarios de la vida.

Dentro de ese rico acervo se encuentra un patrimonio de carácter documental que conviene subrayar por sus posibilidades para el trabajo patrimonial. Se trata de la cartografia de las ciudades históricas, un documento indispensable para el conocimiento y para cualquier actividad de investigación, de protección y, en general, de gestión patrimonial sobre ellas.

De entrada, su aprecio se basa en su utilidad como herramienta directa de conocimiento. Ello es debido a su elaboración, mediante diferentes estrategias gráficas y de acompañamiento literario, que han insistido en mostrarnos -con diversa precisión- la forma y estructura de las ciudades, de sus elementos constitutivos, de sus nombres... Pero también han resultado especialmente ejemplares en cuanto interpretaciones de una realidad que nos aportan valores y significaciones de lo urbano, de una forma relevante. Puede decirse que estas cartografias tienen la capacidad de determinar muy seriamente nuestra percepción global de lo urbano, en estrecha relación con la imagen que proyectamos del pasado, desde nuestras coordenadas culturales contemporáneas. Pero también nos enseñan a leer de otra forma nuestros escenarios cotidianos.

En consecuencia, han condicionado nuestros juicios, y por ello es importante entender su papel, profundizar en su cualidad. Una premisa fundamental es que las representaciones cartográficas de las ciudades se han efectuado insistente y secularmente, pero para muy distintas finalidades y bajo muy diferentes ideas de ciudad. 
La creciente intensidad manifestada en la difusión de ideas, textos e imágenes, en el desplazamiento de personas y mercancias, a partir de la salida del mundo medieval, se tradujo en el auge de la cartografía en sus distintas escalas, desde la representación del conjunto entonces conocido de continentes y océanos, hasta llegar al nivel de lo urbano. Por lo que respecta a este último paso, se dio la combinación de la imagen creativa de una ciudad concreta, insólita, junto a la producción de repertorios que, bajo patrones comunes, permitian un viaje a distintos puntos del globo, donde las ciudades concentrarian fama y excelencia a partir de un particular modo de mostrarse. Unos elencos figurativos que en general alentaron la preferencia por las vistas de ciudades a lo largo de mucho tiempo. Convivieron con fórmulas hibridas entre la vista y el plano de ciudad, basadas en imágenes oblicuas, visiones elevadas, a vista de pájaro (terminologia común a otras lenguas: i.e. $\dot{a}$ vu d'oiseau, o bird's-eye view), que empleaban la perspectiva, generalmente caballera, para definir la posición de edificios y viales, o se deformaban en aproximaciones a una cónica, mediante una ligera convergencia de las líneas de su soporte horizontal.

La representación de Venecia de Jacopo de'Barbari (1500) es un exponente de esa imagen creativa, densa e impar, dentro de una copiosa dinastía donde abundará la seriación y la imitación. En coordenadas más próximas encontramos opciones bien alejadas entre sí. El conocido plano de Madrid del portugués Pedro de Teixeira (1656) insiste en la ciudad como un hecho edificatorio compacto, donde el entorno que lo acompaña subraya su singularidad. Mientras que una representación más selectiva, como la de la capital cordobesa recogida por el canónigo José Vázquez Venegas, apuesta por mostrar únicamente determinados referentes urbanos, de base arquitectónica: defensas, puente, arquitectura de iglesias y conventos (GARCÍA ORTEGA; GÁMIZ GORDO, 2010: 39-40).

Los planos topográficos definidos ortogonalmente, en cuanto plantas urbanas, tardaron en imponerse a las representaciones iconográficas de las ciudades, salvo en determinadas instancias. Surgieron frecuentemente como cartas, insertas por lo común en libros, frente a las vistas de ciudades. Ejemplo crucial fue el plano de Roma de Leonardo Bufalini (1551), donde aparecen numerosas plantas de destacados edificios de distintas épocas, subrayando ese inabarcable patrimonio edificado. A pesar de su novedad, convivió con las cartografías romanas en perspectiva de Lafréry (Speculum romanae magnificentiae de 1555), o de Tempesta (1593), por recordar algunas muy influyentes.

El legado de Bufalini se actualiza y amplía conceptual y formalmente en la detallada y elocuente Pianta Grande di Roma de Giambattista Nolli (trazada entre 1736 y 1748, año de su publicación). En ella se realiza la indicación de las plantas de los principales edificios, fundiendo el espacio público con los interiores de los edificios, que quieren hacerse permeables. La idea de espacio arquitectónico se infiltra y simultáneamente se expande por toda la ciudad. Nolli emblematiza la dimensión arquitectónica de las ciudades ${ }^{1}$, anuncia el énfasis ilustrado por la precisión de las imágenes urbanas, una idea extendida en las representaciones del siglo XVIII de ilustradores, cartógrafos, arquitectos e ingenieros.

Aunque en la España ilustrada sobresalen nuevos instrumentos de la Administración que emplean la cartografia, como son las Respuestas generales del Catastro del Marqués de la Ensenada (1749-1756), las visiones esquemáticas de poblaciones y los predios cercanos, por tanto de base territorial, no eluden una representación urbana de corte naif, pero eficaz a sus propósitos. El Atlas geográfico del Reyno de España e Islas Adyacentes de Tomás López (1758) combina esa inercia con representaciones de planos de ciudad, como la de Oviedo, de planta detallada y minuciosa, anticipadora de criterios visibles un siglo después en importantes cartografías urbanas posteriores, como las de Francisco Coello en el Atlas de España y sus posesiones de Ultramar (1847-1870), para complementar el Diccionario geográfico-estadístico-histórico de España y sus posesiones de Ultramar de Pascual Madoz.

Pero el proceso no fue estrictamente lineal. Asi, Isaac Basire, en 1745 y para su plano de Gibraltar (Plan of the Town and Fortifications of Gibraltar, exactly taken on the Spot in the Year 1738: For Mr. Tindal's Continuation of Mr. Rapin's History of England), armoniza una planta rigurosa de la ciudad, morfológicamente nítida, con la peculiaridad de emplear la vista oblicua para el Peñón, defensas y muelles, reforzando por la distinción gráfica tridimensional su impronta física.

\section{MATICES PARA EL GOBIERNO DE LA CIUDAD HEREDADA}

Sin embargo, en este mezclado panorama, la proyección vertical ortogonal, más racional, aparece definida y empleada convencionalmente para expresar una comprensión más ajustada de aspectos dimensionales y posicionales: escala, distancia, altura, etcéte-

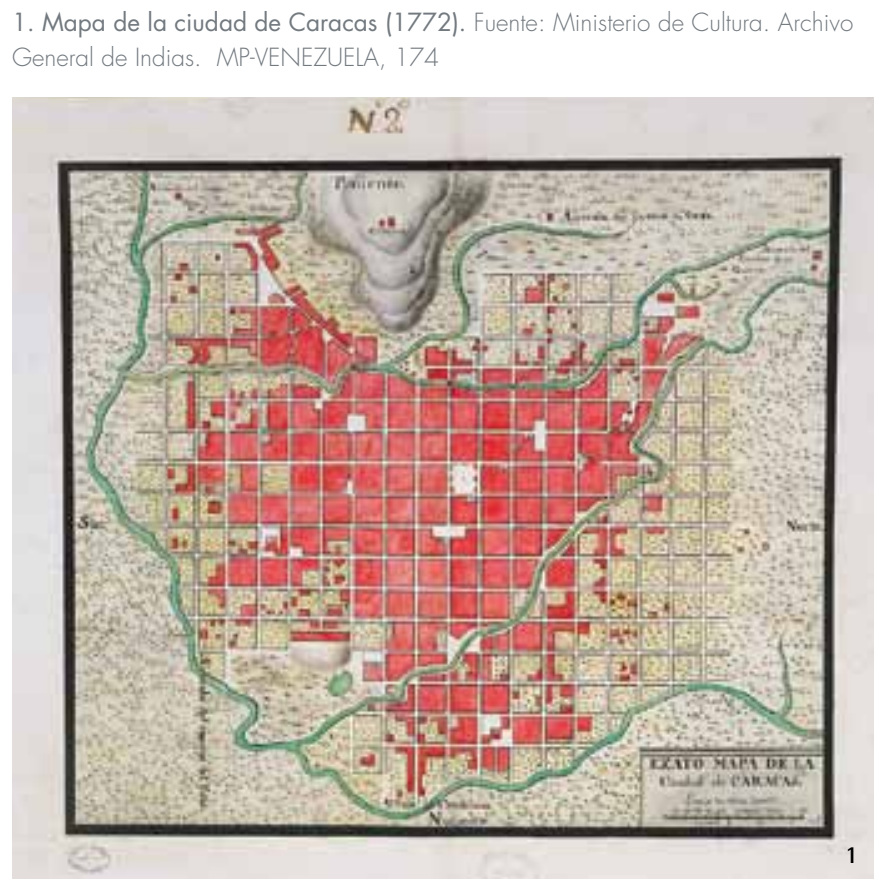


ra, que deben estar perfectamente controlados. Al tamaño de la edificación, la latitud del viario y la precisa posición de las cosas, se les suele agregar además el manejo de información detallada del nomenclátor urbano. Lo que nos permite dilucidar de un vistazo la funcionalidad de algunos espacios y ámbitos urbanos.

La solución vertical diferencia estudiadamente, por ejemplo, lo construido frente a los vacios urbanos del viario; realza el verde (huertas, paseos, jardines...) y los cauces; distingue el sistema defensivo con las murallas, sus torres y puertas. Suele resultar llamativo el habitual elenco de convenciones, por ejemplo, para representar la arquitectura religiosa, cementerios...

La idea de conocimiento volcado a la cartografía, flota no solo en la identificación de hitos urbanos de la ciudad habitada. En el caso de Mérida, el plano de Moulinier y Vicq nos muestra cómo la presencia de la arqueología, de los bienes arqueológicos, define la periferia urbana, le otorga una cualidad. Los grandes edificios públicos romanos (teatro, anfiteatro, circo...) o el acueducto de San Lázaro son realidades disponibles, que forman parte de la ciudad. Aunque todavía está lejos el tiempo de su patrimonialización, de su integración plenamente activa en un discurso urbano.

El conocimiento es una llave en el gobierno de la ciudad. El Mapa de Coelho de la ciudad de Sevilla, levantado para el asistente Pablo de Olavide y grabado por Joseph Amat en 1771, combina la representación de manzanas, huertas y viales, con una esquemática figuración de numerosos edificios, e incluso elementos del ahora llamado mobiliario urbano.

Ocurre que la esencia laberintica de la ciudad alberga un caudal considerable de edificios, que debe desbrozar la cartografía. Otorgándoles una carga icónica, se individualizan y asumen un papel en el largo listado que flanquea en ambos extremos al plano. La imagen de Sevilla aparece enmarcada y sostenida entre dos poderosas columnas tipográficas, expresivas de su detalle, de su entraña arquitectónica y funcional, hecha esencialmente de hitos de repercusión pública colectiva, de instancias propias de unos modos de vida del Antiguo Régimen, en pronto redimensionamiento y desaparición².

Y este progreso de la cartografía topográfica setecentista se emplea con un especial acento cuando se dedica a los puertos y los espacios portuarios. Caminos, puentes, obstáculos geográficos, a pesar de su mayor abstracción, ven reforzado su protagonismo. Los materiales del proyecto ilustrado de ciudad se reconocen, en definitiva, en la imagen urbana. Materiales que son base de las políticas urbanas sobre la ciudad heredada y lo son para el despliegue de nuevos escenarios urbanos: nuevas poblaciones, arsenales, ciudades factoría...

\section{LA CIUDAD PROYECTADA}

La ciudad, como la sociedad contemporánea que emerge, se encuentra en evolución: en las cartografías se refleja un instante de la vida urbana, pero a menudo se acompaña de trazados proyectados, del destino que se puede atisbar.

Es muy importante para el trabajo patrimonial, por cuanto permite observar el grado de apoyo o de diferenciación del proyecto respecto a la base urbana existente y, por tanto, la estima de la operatividad de la trama heredada.

Existe toda una tradición cartográfica al respecto, que arranca del siglo XVI y se patentiza en su perfeccionamiento en las dos centurias siguientes. Hay que referirse a los planos de las ciudades hispanas fundadas en el Nuevo Mundo y Filipinas. El trascendente hecho fundacional y su repercusión en la cartografía nos recuerda el trazado de estas ciudades: el empleo de la cuadrícula, con las cuadras como receptoras de la edificación, liberando en el centro la plaza de armas, y creciendo hacia los cuatro puntos cardinales salvo impedimento de un accidente geográfico.

Basta contemplar el plano de Caracas, conservado en el Archivo General de Indias, para apreciar la radical importancia de la trama de la cuadrícula y su flexibilidad para asumir el crecimiento. Las representaciones de Buenos Aires, desde el loteo inicial del siglo $X V I$, abundan en la trama como determinante de la futura expansión, de un crecimiento al que en el siglo XVIII o XIX no se le ponen límites. Es la cartografía de la previsión de una prolongada dinámica de cambio, que nos trae el problema de los tiempos de las ciudades y su capacidad para transformarse.

La trama no siempre se plantea como algo ligado a un crecimiento abierto. A menudo, como en la vieja España (por ejemplo, la nueva población en la isla de Tabarca), se pusieron límites a este modo de producción de ciudad: las peruanas Trujillo y Lima, San Juan de Puerto Rico y tantos puertos en el entorno caribeño lo requirieron, entre otros casos. Esto expresa una condición urbana muy precisa, derivada de situaciones geoestratégicas tensadas, por ejemplo.

Un caso más cercano de representación ilustrada de la ciudad proyectada es el de la nueva población de San Carlos, en la gaditana Isla de León. La cartografía expresa la ciudad en construcción, un detalle de importancia en una carta naval del notable cartógrafo Vicente Tofiño, al detenerse especialmente en determinados ámbitos urbanos. Por ejemplo, indica textualmente: "Población de S. Carlos proyectada". Y de algunos de los elementos destaca, marcando la importancia de la situación actual y su proyección, que se encuentran en proceso de ejecución:

"2. Iglesia, empezada su fábrica [...] 9. Cuarteles de Batallones, empezados [...] 11. Darsena y Caños, empezados" [sic]. Todo un documento gráfico de la progresiva ocupación de los terrenos ordenados.

Pero no siempre nos encontramos con actos fundacionales, con su hacerse, con su crecimiento. Las cartografias urbanas nos plantean también la reforma urbana con sus múltiples instrumentos y mecanismos, exponentes de su riqueza, de su patrimonio urbanístico. 

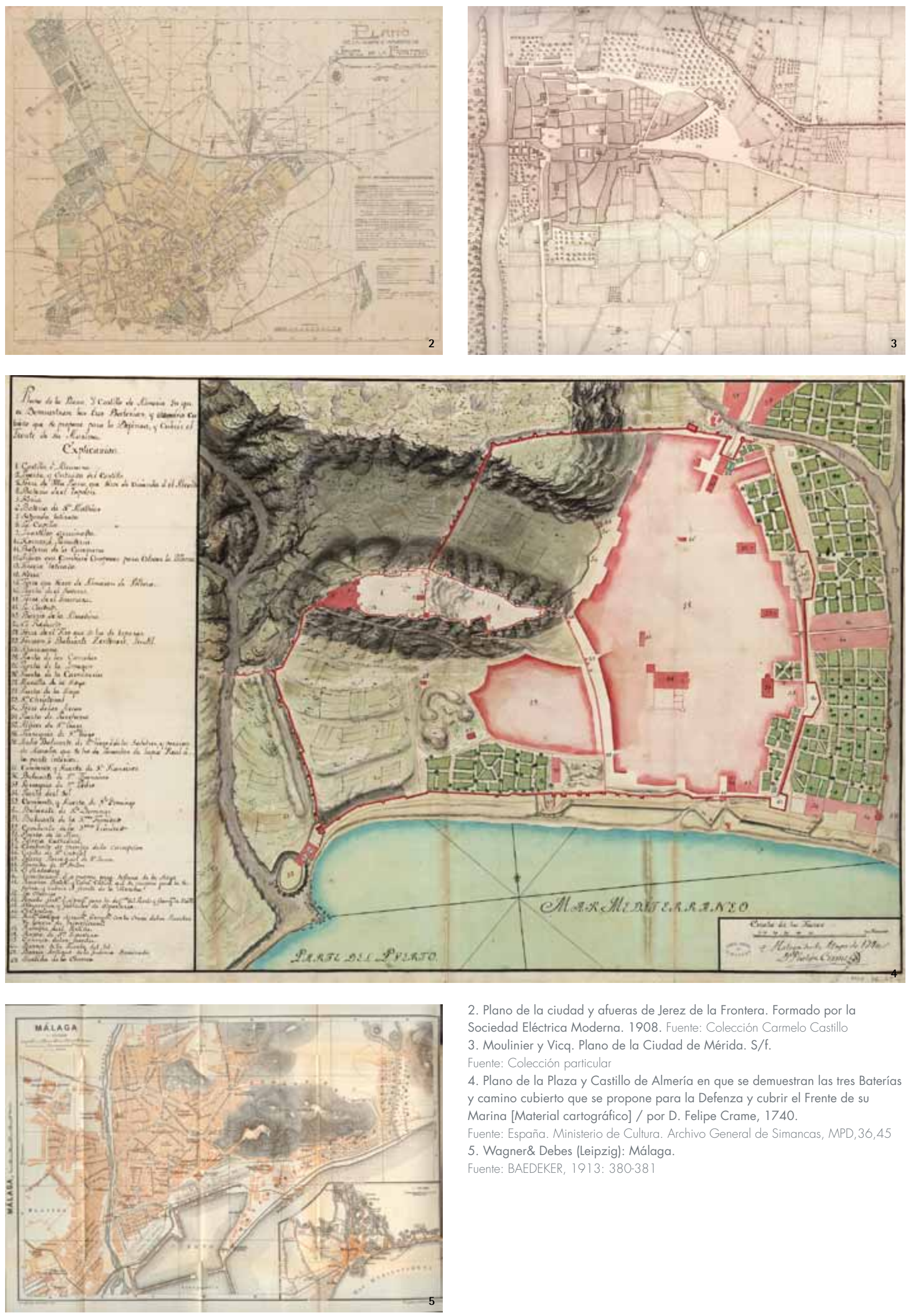

2. Plano de la ciudad y afueras de Jerez de la Frontera. Formado por la Sociedad Eléctrica Moderna. 1908. Fuente: Colección Carmelo Castillo

3. Moulinier y Vicq. Plano de la Ciudad de Mérida. S/f Fuente: Colección particular

4. Plano de la Plaza y Castillo de Almería en que se demuestran las tres Baterías y camino cubierto que se propone para la Defenza y cubrir el Frente de su Marina [Material cartográfico] / por D. Felipe Crame, 1740.

Fuente: España. Ministerio de Cultura. Archivo General de Simancas, MPD, 36,45

5. Wagner\& Debes (Leipzig): Málaga

Fuente: BAEDEKER, 1913: 380-381 
Un caso andaluz extremadamente interesante es el del redimensionamiento de Almeria por retracción. Esta circunstancia exigió el trazado de nuevas murallas al interior de la primitiva cerca, mermada su población, para garantizar una mejor defensa de la ciudad en sus nuevos límites. Las cartografías del XVII, de Juan de Oviedo, arquitecto e ingeniero vinculado a dicho menester, o del XVIII, de Felipe Crame, son claramente explícitas.

Acontecimientos sobrevenidos, como el terremoto de Lisboa de 1755, determinaron el nuevo trazado de la Lisboa pombalina. Las cartografías de Eugenio dos Santos y Carlos Mardel nos permi-
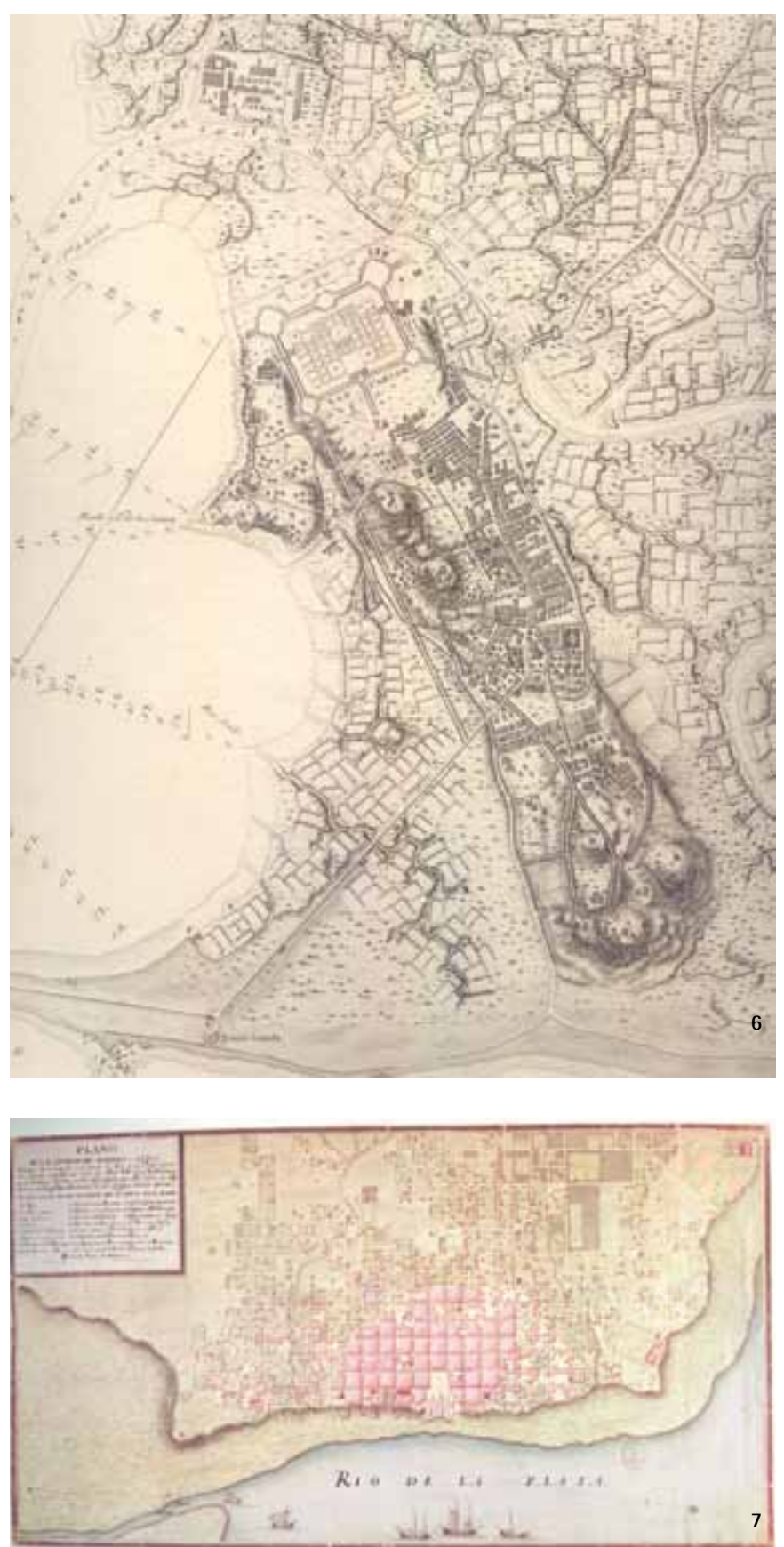

6. Vicente Tofiño de San Miguel. Plano del Puerto de Cádiz. Levantado por el brigadier de la Real Armada V T SM Director de las Academias de Guardiamarinas. AÑO MDCCLXXXIX. Fuente: Colección particular

7. Plano de la ciudad de Buenos-Ayres. Fuente: S/f. Archivo del Servicio Histórico Militar, Madrid. Ref. $\mathrm{n} .06 .267$, hoja $1 / \mathrm{Pb} .10-27$ ten vislumbrar el cambio urbano que se registraria en la Baixa o el Bairro Alto, empleando cuidadosamente un tratamiento cromático diferenciado: lo existente, lo que desaparece y lo nuevo proyectado.

El urbanismo del XIX nos legó una cuidada manera de cartografiar los procesos urbanos, haciendo hincapié en su naturaleza. Por ejemplo, resulta clásico acudir a John Nash y su diseño renovador para la londinense Regent Street (1811-25), donde se atiende especialmente a representar la afección al parcelario del nuevo trazado.

La moderna urbanistica, con su proverbial pragmatismo, afronta la cuestión de la cartografía no sólo con la debida precisión gráfica. Ildefonso Cerdà, padre de la Teoría General de la Urbanización, en su "Proyecto de Reforma y Ensanche" asume el tratamiento destacado de lo existente, aunque indiferenciado en sí mismo, por el empleo de una trama uniforme. Son momentos para pensar básicamente en el carácter de las nuevas estructuras urbanas.

\section{NUEVAS ESPECIFICIDADES}

La idea contemporánea de ciudad y los mecanismos para su gestión y rentabilización evolucionaron velozmente. Basta recordar el desarrollo de la Urbanistica y el tiempo del Arte Cívico, con el modo de cartografiar de Werner Hegemann, o de Camillo Sitte para la ciudad histórica, hasta el más evolucionado de Martin Wagner. Por ello, las cartografías que entren en escena a partir de ese momento serán el resultado de nuevas especificidades, de nuevas formas e intereses de conocimiento.

Así, se producen notables cartografias municipales o de empresa: redes de alcantarillado y suministro de agua, alumbrado público, pavimento y acerado, líneas de electricidad, líneas de transporte... aparecen de una forma determinante. Vectores de la nueva calidad de la vida urbana emergen de esta manera en las cartografías. Es el caso de la Sociedad Eléctrica Moderna, que en 1908 traza un notable y detallado plano de la capital jerezana y sus alrededores. En él se pone énfasis en ofrecer abundantes datos e informaciones gráficas y escritas. Pero sobresale el interés por mostrar el progreso de una nueva infraestructura asociada a la electrificación. El plano especifica las líneas de los tranvías, indicando las del "proyecto aprobado, como de inmediata construcción". Mientras que parte del proyecto será de "construcción posterior" y asimismo existen otras líneas "en estudio".

En una sociedad evolucionada, sus ciudades son objeto de atracción del turismo. Algunas empresas editoras de guias turísticas cuidarán especialmente los mapas y planos de ciudades que las ilustren. Es importante porque se maneja una cartografia rigurosa. Debe decirse que en esto los planos que publica Baedeker son ejemplares; su cartografía está definida con la conveniente manifestación de los objetivos e informaciones recomendables a un turista culto, dentro de dicho destino. La ciudad aparece por lo tanto marcada por el destacado de diversos elementos. 
En primer lugar, el hecho del viaje es determinante. Tomemos una ciudad marítima como Málaga (BAEDEKER, 1913: 380-381), los lugares de arribada (puerto, estación de ferrocarril, carreteras...) y los de estancia, como los hoteles, se combinan con la visita: ante todo el viario, jardines $y$, por supuesto, los monumentos. Por lo tanto, la ciudad muestra otros elementos. Presente y pasado se entremezclan, y potencian el sesgo que la marca turistica de las ciudades adquiere, donde el patrimonio obtiene un protagonismo, sin olvidar a la ciudad como teatro cartografiado del beneficio empresarial.

Es interesante hacer el ejercicio de comparación de estas cartografias con una estudiada expresión de nuestros hechos urbanos como es el trabajo del arquitecto Jürgens. Las cartografías de Oskar Jürgens nos hablan de muchas ciudades andaluzas ${ }^{3}$ que, en varios casos, apenas en 1923, trascendian de sus viejos límites amurallados.

El marcado de edificios singulares, el cuidado en el dibujo de los espacios públicos, revela un grafismo de éxito prolongado en el tiempo. El arquitecto Pons Sorolla lo aplicó todavía en algunos planos relativos a ciudades históricas hasta los años sesenta del siglo $X X$, incluso arquitectos posteriores lo hicieron al delimitar conjuntos históricos.

Tras Jürgens, los derroteros de la urbanistica española, de la mano de César Cort o de Gustavo Fernández Balbuena nos llevan a un rediseño cartográfico capaz de expresar la moderna operativa del planeamiento urbanístico previo a la guerra civil. Con Fernández Balbuena asistimos a la aplicación de cartografía de temprana base patrimonial a una ciudad histórica como Ciudad Rodrigo.

Unos años antes, en el giro del siglo XIX al XX, conviene señalar, se habian elaborado los planos de población por parte del Instituto Geográfico y Estadístico. Se trata de unos planos que permiten definir con bastante precisión las alteraciones a que se ha sometido el conjunto de la trama con realineaciones, aperturas, ocupaciones de vías públicas, etc. Son especialmente indicados para precisar la evolución de nuestras ciudades, no ya en términos de mancha de crecimiento, según la cartografía del urbanismo moderno post-Atenas, sino en la microescala, parcela a parcela, que requiere el planeamiento que se destina a proteger el patrimonio.

Hablando algo de nuestras cartografías cotidianas, decir que los planos parcelarios de urbana y de rústica son recientes. Se parte con las anotaciones de los años treinta, avances de los cincuenta y planos parcelarios generalizados a partir de los años setenta, ejecutados con precisión variable. Son también un instrumento cartográfico indispensable para leer la evolución de nuestras ciudades históricas, más acelerada en algunos momentos de lo que pudiera pensarse.

El urbanismo zonal de manchas, de origen citado anteriormente, ha producido otra imagen de las cartografias que hablan del cambio urbano, de las acciones que posibilitan el desarrollo urbano. Son las cartografías derivadas del planeamiento expansivo, el propio de hacer ciudad, una tarea siempre inacabada, como el propio progreso en la manera de representar nuestras ciudades y su complejidad cultural, que es particularmente exigente respecto al planeamiento que se mide con la gestión patrimonial. Quizá en nuestra órbita cultural haya sido el Laboratorio de Urbanismo de Barcelona, con el impulso de Manuel Solà-Morales, quien ha alentado la reflexión sobre las modernas cartografias de nuestras ciudades y territorios heredados.

Pero hoy, más que nunca, mantienen su actualidad aquellas observaciones de Michel Foucault: "en la percepción de las implantaciones, de las delimitaciones, del perfilamiento de los objetos, de los gráficos, de las organizaciones, de los dominios, lo que se hacia aflorar eran los procesos - por supuesto históricos- del poder. La descripción espacializante de los hechos del discurso desemboca en el análisis de los efectos de poder que están ligados a ellos" (FOUCAULT, 1978: 118). En el fondo, las cartografias deben estar llamadas a trazar otros despliegues más compartidos de la cultura de nuestras ciudades.

\section{Notas}

1 Su eco se traslada hasta la mirada sobre la ciudad histórica y la producción de la Tendenza, o el concurso de Roma Interrotta (1978).

2 Nos referimos al hecho de que, por ejemplo, en 1767 ya se ha expulsado a la Compañía de Jesús de las siete casas que, especificadas en el plano con los números que van del 70 al 76, poseian en la ciudad. Es decir, cuatro años antes de la edición del documento cartográfico.

${ }^{3}$ Incluye Córdoba, Granada, Sevilla, Málaga, Cádiz y Algeciras. Es decir, seis de un total de veintisiete que selecciona de toda España.

\section{Bibliografía}

BAEDEKER, K. (1913) Spain and Portugal. Handbook for Travellers. Leipzig: Karl Baedeker; Londres: T. Fisher Unwin; Nueva York: Charles Scribner’s Sons, 1913 (4ª ed.), 1898 ( 1 a ed.)

FOUCAULT, M. (1978) Preguntas a Michel Foucault sobre la geografía. Microfísica del Poder. Madrid: Las Ediciones de La Piqueta, 1978

GARCíA ORTEGA, A. J.; GÁMIZ GORDO, A. (2010) La ciudad de Córdoba en su primer plano: un dibujo esquemático de 1752. Archivo Español de Arte, v. 83, n. ${ }^{\circ}$ 329, 2010, pp. 23-40

JÜRGENS, O. (1992) Ciudades Españolas. Su configuración y desarrollo urbanistico. Madrid: MAPA, 1992 (1 ${ }^{\text {a }}$ ed. alemana, 1926)

MAIER, J. (2007) Mapping Past and Present: Leonardo Bufalini's Plan of Rome (1551). Imago Mundi: The International Journal for the History of Cartography, v. 59, n. ${ }^{1}$, 2007, pp. 1-23

MARTín LÓPEZ, J. (2002) Historia de la Cartografía y de la Topografía. Madrid: Centro Nacional de Información Geográfica del Ministerio de Fomento, 2002 PINTO, J. A. (1976) Origins and Development of the Ichnographic City Plan. Journal of the Society of Architectural Historians, v. 35, n. ${ }^{0} 1$, marzo 1976, pp. 35-50

QUIRÓS LINARES, F. (2010) La cartografía de la metrópoli en el Atlas de España y sus Posesiones de Ultramar (1847-1870), de Francisco Coello. Características, fuentes y colaboradores. Ería, 81, 2010, pp. 63-92

SAMBRICIO, C. (1996) De los libros de viajeros a la historia urbana: el origen de una disciplina. Ayer, 23, 1996, pp. 61-85 